\title{
PEDIATRIC OSTEOMYELITIS AND SEPTIC ARTHRITIS: 10-YEAR OVERVIEW OF A PORTUGUESE HOSPITAL
}

Pedro Marinho1; Ana de Carvalho Vaz"; Francisco Ribeiro-Mourão1; Vera Gonçalves ${ }^{1}$; Mariana Costa ${ }^{1}$ 1 Serviço de Pediatria da Unidade Local de Saúde do Alto Minho

The authors present a retrospective observational study including all patients younger than 18 years, admitted in our Pediatrics department between $04 / 2008$ and $04 / 2018$, with diagnosis of OM or SA. Data regarding the patient, diagnosis, treatment and follow-up was analyzed.

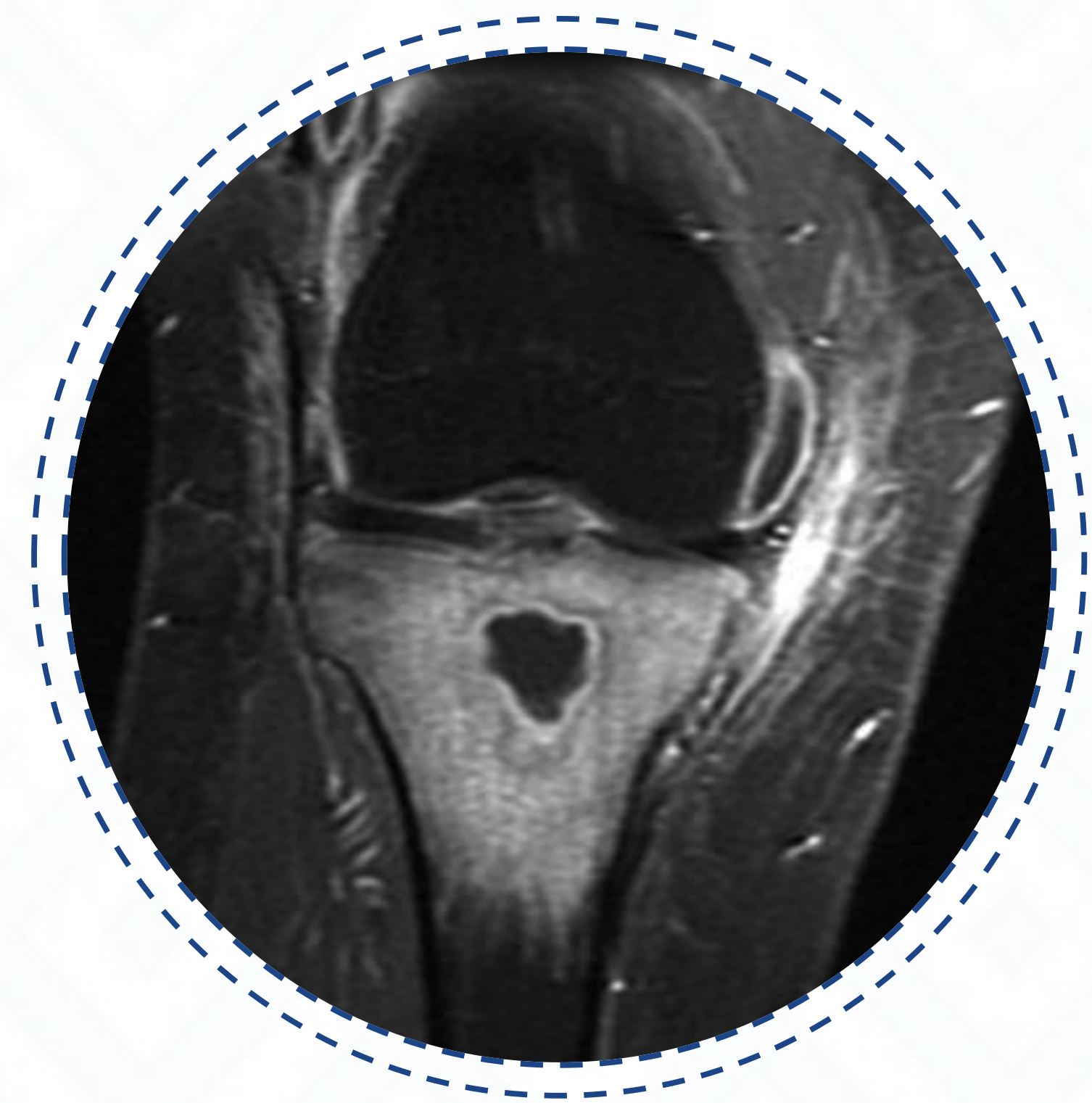

Osteomyelitis (OM) is an infection localized to bone, while Septic Arthritis (SA) is an infection of the joint, both usually due to bacterial infection.

This overview aims to characterize the patients, diagnosis and treatment of OM and SA cases diagnosed in a Pediatrics department of a Portuguese hospital, over a 10-year period.

\section{OSTEOMYELITIS}

\section{$n=12$}

66,7\% Avg. Age $=9,8$ years [ 3 months -15 years]

- $100 \%$ of cases presented with pain, with an average of $\mathbf{5 , 9}$ days of pain before admission to the Emergency Service.

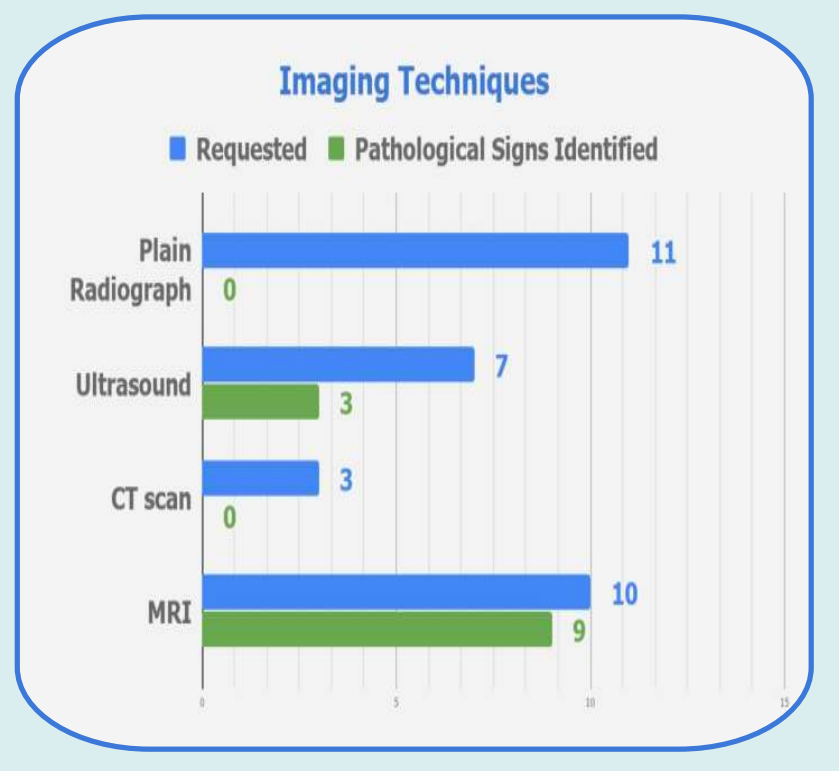

- $\mathbf{7 5 , 0} \%$ presented with fever.

- With imaging techniques, no pathological signs were found in $\mathrm{CT}$ scans, but were described in $90 \%$ of MRI's.

- $33,3 \%$ of patients underwent surgical procedure.

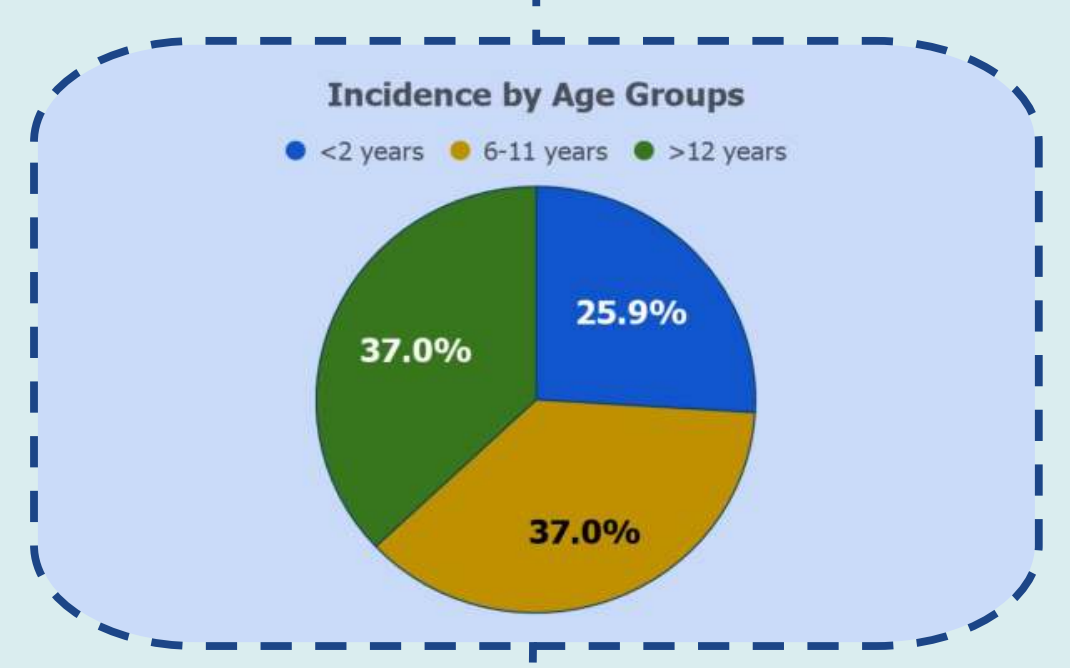

SEPTIC ARTHRITIS

$n=14$ Service.

$50,0 \%$ Avg. Age $=7,7$ years [ 12 days -17 years]

- $100 \%$ of cases presented with pain, with an average of 4,8 days of pain before admission to the Emergency

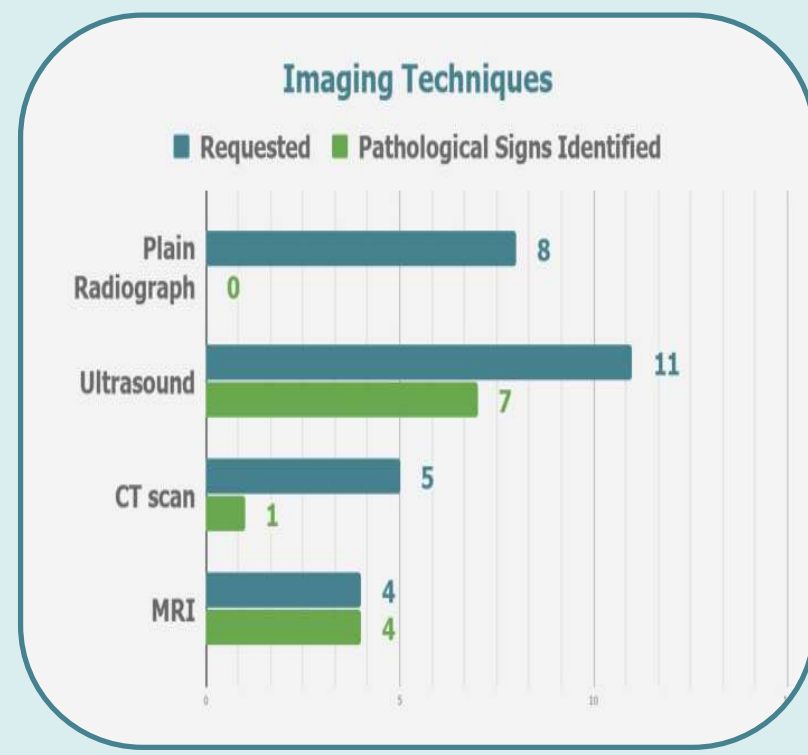

- $\quad \mathbf{4 2 , 8} \%$ presented with fever.

- With imaging techniques, pathological signs were described in $63,6 \%$ of Ultrasounds and in $100 \%$ of MRl's.

- $57,1 \%$ of patients underwent surgical procedure.

\section{DISCUSSION}

Despite being a rare diagnosis, prompt recognition and treatment of OM and SA can help prevent long-term disability. Pain seems to be the most prevalent presentation, but clinical awareness is paramount. 